\section{The interhemispheric transfer of movement aftereffects: A comparison between acallosal and normal subjects}

\author{
N. F. DIXON, University College, London, England \\ and \\ M. A. JEEVES, University of St. Andrews, St. Andrews, Fife, Scotland
}

Movement aftereffects induced by the viewing of rotating random patterns were measured for normal and (three) acallosal Ss. Whereas the two groups did not differ in the extent to which they showed monocular and binocular movement aftereffects, interocular transfer was significantly more pronounced for the normal than for the acallosal Ss.

Despite numerous studies (Wohlgemuth, 1911; Holland, 1965; Taylor, 1963; Pickersiill \& Jeeves, 1964; Anstis \& Gregory, 1965; Dixon \& Meisels, 1966), the physiological bases of movement aftereffects (MAEs) remain far from clear. Data from these studies suggest the following: (1) Aftereffects resulting from perceived real movement are mediated by the image/retina signaling system. (2) The extent of an aftereffect is positively related to viewing time, velocity up to a certain level, and information content of the inducing field. (3) The potential for an MAE can be "stored" during a dark period between presentation of the inducing field and presentation of the test field. (4) Interocular transfer usually occurs, if only slightly, for most movement aftereffects.

Thus far, the evidence, particularly that relating to transfer and storage, could be taken to imply that MAEs depend largely, if not exclusively, upon central mechanisms, a view favored by several workers (Scott \& Wood, 1966; Barlow \& Brindley, 1963; Richards \& Smith, 1969).

There are, however, contrary opinions. Day (1958) has argued that since each eye projects to both visual cortices there is no need to postulate a central process. According to this view, aftereffects from the previously stimulated eye could interact with the sensory inflow from the test eye. That aftereffects will transfer between hemiretinae projecting to the same hemisphere but not between those projecting to different hemispheres has been shown by Walls (1953) and Freud (1962).

Also favoring a peripheral explanation is the finding that unidirectional movement detectors, as located in the retinae of subhuman species (Barlow \& Hill, 1963), could provide, if existent in humans, a simple physiological basis for MAEs. When a rabbit's eye is exposed to a rotating black-and-white disk, only a proportion of the movement detectors in the animal's retina become active. Cells "wired up" for the detection of movement in the opposite direction remain quiet apart from their normal spontaneous discharge of around 15 impulses/second. When the moving stimulus is withdrawn, however, the cells that have been mediating visual motion become completely silent for up to $30 \mathrm{sec}$. It has been suggested that in comparison with their lack of activity the continuous spontaneous discharge of the adjacent null direction detectors could now produce a movement aftereffect.

Finally, the finding (Pickersgill \& Jeeves, 1964) that interocular transfer of a MAE can be prevented by poststimulation pressure blinding of the eye that was exposed to the inducing stimulus appears to indicate that the phenomenon has a purely retinal origin. It should be noted, however, that this effect of pressure blinding has not been confirmed by other workers (Barlow \& Brindley, 1963; Scott \& Wood, 1966).

Of particular interest in this controversy is the role, if any, of the corpus callosum. Since interocular transfer of a learned pattern discrimination in cats (Myers, 1956; Sperry, Stamm, \& Milner, 1956) appears to depend upon an intact, or partially intact, corpus callosum, one might suppose that this structure also mediates bilateral transfer of a movement aftereffect. There are, however, two contraindications additional to Day's (1958) argument that the two retinae project bilaterally. In the first place, the split-brain preparations of Myers (1956) had sections not only of the corpus callosum but also of the chiasm. In the second place, it has been shown (Singer \& Day, 1966) that in human Ss with an intact corpus callosum there is intralimb but no bilateral (interlimb) transfer of kinesthetic aftereffects (KAEs) (judging the horizontal aftermovement of an extended limb across a slanted edge).
This lack of bilateral transfer for a KAE is particularly interesting in view of the fact that, as Singer and Day have pointed out, the afferent flow from both sides of the body converges upon the second somatic sensory area (Houssey, 1955; Mountcastle, 1961).

If juxtaposition of afferent projections from the two eyes account for interocular transfer of an MAE, then why does the same not hold true for KAEs? One reason might be that the greater necessity for interhemispheric interaction in vision than in kinesthesis necessitates proportionately larger channel space for visual information, as opposed to kinesthetic information, in the commissural systems of the brain. This view agrees with the aforementioned findings regarding bilateral transfer of learned visual pattern discriminations, and with Efron's (1962) work on judgments of simultaneity of visual and other stimulation. It is also consistent with the effects of agenesis of the corpus callosum upon reaction times to a visual stimulus (Jeeves, 1965, 1969).

It was with these considerations in mind that we decided to test the hypothesis that interocular transfer of even a strong aftereffect would not occur in Ss lacking a corpus callosum.

\section{SUBJECTS}

All three Ss were Australians of European descent. Full details of their neurological status and the results of earlier psychological testing are given in Jeeves (1965). They were all enthusiastic and cooperative Ss but, as indicated below, varied in their availability for testing, depending on the distance of their homes from the psychological laboratory.

S 1 was a 14-year-old boy who, since he lived near the laboratory, could come for testing at frequent intervals.

S 2 was a 47-year-old man. He lived more than 100 miles from the laboratory, and thus it was possible to test him only for brief periods when he visited the city on business.

S 3 was a 10-year-old boy. He lived 450 miles from the laboratory, and it was possible to gather only such limited data on him as could be collected during a brief visit by one of the Es (M.A.J.).

$$
\text { METHOD }
$$

To maximize the possibility of interocular transfer, recourse was made to a high-information-content stimulus field which, as previous research (Dixon \& Meisels, 1966; Dixon, 1967; Baker \& Dixon, 1967) has shown, produces low Table 1

Duration of MAEs in Seconds Means of Three Trials

\begin{tabular}{ll} 
Normals $(N=11)$ & 17.4 \\
Acallosal $(N=1)$ & 20.6 \\
\hline
\end{tabular}


Table 2

MAE Duration in Seconds

\begin{tabular}{|c|c|c|c|c|c|}
\hline & RR & LL & RL & LR & IOT \\
\hline & \multicolumn{5}{|c|}{ Acallosals } \\
\hline 1 & 17.9 & 9.1 & 0 & 0 & 0 \\
\hline 2 & 8.0 & 8.5 & 0 & 0 & 0 \\
\hline 3 & 8.75 & 6.87 & 0 & 2.50 & 1.25 \\
\hline \multirow[t]{2}{*}{$\bar{x}$} & 11.55 & 8.15 & 0 & .83 & .41 \\
\hline & \multicolumn{5}{|c|}{ Normals } \\
\hline 1 & 8.05 & 2.70 & 2.16 & 0 & 1.08 \\
\hline 2 & 8.04 & 11.97 & 4.34 & 2.20 & 3.27 \\
\hline 3 & 12.19 & 14.24 & 3.56 & 4.20 & 3.88 \\
\hline 4 & 16.38 & 15.99 & 2.77 & 1.27 & 2.02 \\
\hline 5 & 12.52 & 18.35 & 2.86 & 3.12 & 2.99 \\
\hline 6 & 15.50 & 20.88 & 0 & 0 & 0 \\
\hline 7 & 4.70 & 17.56 & 1.59 & 1.80 & 1.70 \\
\hline 8 & 8.72 & 7.05 & 1.92 & 1.20 & 1.56 \\
\hline 9 & 7.98 & 13.25 & 1.93 & 2.43 & 2.18 \\
\hline 10 & 10.26 & 12.81 & 1.24 & 1.96 & 1.60 \\
\hline 11 & 13.37 & 15.78 & 1.61 & 2.79 & 2.20 \\
\hline 12 & 6.23 & 8.40 & 0 & 0 & 0 \\
\hline 13 & 11.08 & 24.25 & 0 & 3.79 & 1.90 \\
\hline 14 & 8.07 & 14.21 & 2.90 & 0 & 1.45 \\
\hline 15 & 18.02 & 23.15 & 0 & 2.0 & 1.00 \\
\hline 16 & 8.48 & 15.82 & 2.24 & 2.13 & 2.19 \\
\hline 17 & 9.53 & 20.17 & 0 & 1.43 & .72 \\
\hline 18 & 12.80 & 18.30 & 1.04 & 0 & .52 \\
\hline $\bar{x}$ & 10.67 & 15.22 & 1.67 & 1.67 & 1.68 \\
\hline
\end{tabular}

$R R$ signifies stimulus to right eye and test field to right eye

$L L$ signifies stimulus to left eye and test field to left eye

$R L$ signifies stimulus to right eye and test field to left eye

$L R$ signifies stimulus to left eye and test field to right eye

thresholds for visually perceived movement and strong aftereffects of long duration. It consists of a rotating disk bearing a random distribution of black and white squares. Each of these squares $(22,000)$ subtends an angle of $3 \mathrm{~min}$ of arc at a viewing distance of $1 \mathrm{~m}$.

For the experiment, our Ss were seated $1 \mathrm{~m}$ from the stimulus disk, which was rotated at $10 \mathrm{rpm}$. After the viewing period, the disk was overlaid by the test field, a sheet of gray matt paper. Instructions to the $S$ were simply to report the cessation of any aftereffect he might see following presentation of the test field. 1

Prior to the main experiment, a pilot study was run to compare one acallosal $S$ with the group of normals tested by Dixon and Meisels. Table 1 shows the mean aftereffect durations for both normals and the acallosal following $20 \mathrm{sec}$ of stimulation with the inducing field.

Evidently the absence of a corpus callosum makes little difference to the aftereffect induced by a random field. It was noticed, however, that whereas interocular transfer occurred for the normals it was totally absent in the case of the acallosal S.

For the main experiment, the performance of the three acallosal Ss was compared with that of 18 normals. On half the monocular trials, the test eye was the same as the stimulated eye, on the other half the stimulated eye was occluded immediately after viewing the rotating field and the test field exposed to the unstimulated eye. Viewing time of the stimulus field was $20 \mathrm{sec}$ in every case.

\section{RESULTS}

The durations of the aftereffect for the

These data indicate that, while the stimulated eye mediates an aftereffect comparable with that obtained from normals, there is a complete absence of interocular transfer in the two acallosals viewing a gray test field and almost complete absence in the $S$ who continued to view the disk after it had come to a halt (for this $\mathrm{S}$, the four IOT scores from which the means in Table 2 were computed comprised $0,5,0$, and 0 , respectively). The difference between mean interocular transfer for normals and acallosals is significant at the $3 \%$ level of confidence $(t=1.99)$.

\section{DISCUSSION}

If not coincidental, the relative lack of interocular transfer in acallosal as opposed to normal Ss is by no means easily explained. On the one hand, since each eye projects bilaterally, there is no a priori reason why information received by the test eye should have to cross between the hemispheres in order to make contact with stimulus effects mediated by the other eye. On the other hand, since all three of our acallosal Ss showed strong monocular (as well as pronounced binocular) aftereffects, it cannot be claimed that the aftereffect per se depends upon any interhemispheric interaction mediated by the corpus various conditions are shown in Table 2 . callosum. There remain two possible explanations of our findings. The first is that the corpus callosum is involved in a storage function that only becomes necessary when the tested eye differs from the stimulated eye. The second is that interocular transfer depends upon inhibitory or excitatory effects between homotopically related foci in the two visual cortices.

There is one final point. Indirect evidence for the role of the corpus callosum in interocular transfer has come from subsequent research (Dixon, in preparation ${ }^{2}$ ) into the effects of simultaneous presentations of two contrary rotating inducing fields upon subsequent apparent movement. Ordinarily, such contrary rotating fields cancel each other out and produce no aftereffects. But, provided the two stimulus fields are presented, one to one eye and the other to the other, and provided presentation of the subsequent test field is alternated between the two eyes, the $S$ reports seeing a single surface moving first in one direction and then in the other. From this finding, that two contrary aftereffects may be "stored" simultaneously and without mutual cancellation in a single hemisphere, it seems justifiable to conclude that the juxtaposition of the projections from the two eyes in a single hemisphere is insufficient to account for interocular transfer. But if the projections from the two eyes to a single hemisphere show sufficient functional separation to prevent mutual cancellation of opposing aftereffects (and therefore interocular transfer) then the latter phenomenon would seem to implicate activity in the corpus callosum.

\section{REFERENCES}

ANSTIS, S. M., \& GREGORY, R. L. The after-effect of seen inotion: The role of retinal stimulation and of eye movements. Quarterly Joumal of Experimental Psychology, 1965 17, 173-174.

BAKER, E., \& DIXON, N. F. A note on field dependency and movement after-ffects. British Journal of Psychology, 1967, 58. 459-462.

BARLOW, H. B., \& BRINDLEY, G. S. Interocular transfer of movement after-effects during pressure blinding of the stimulated eye. Nature, 1963, 200, 1347.

BARLOW, H. B., \& HILL, R. N. Selective sensitivity to direction of movement in ganglion cells of the rabbit retina. Science, $1963,139,412-414$

DAY, R. H. On interocular transfer and the central origin of visual after-effects. American Journal of Psychology, 1958, 71, 784-790.

DIXON, N. F. Effect of information content and size upon the absolute threshold for movement. Perceptual \& Motor Skills, 1967 $25,37-40$.

DIXON, N. F., \& MEISELS, L. The effect of information content upon the perception and after-effects of a rotating field. Quarterly 
Journal of Experimental Psychology, 1966, $18,310-318$.

EFRON, R. The effect of handedness on the perception of simultaneity and temporal order. Brain, 1962, 86, 261-284.

FRELD, S. L. A study of physiological mechanisms underlying the spiral after effect. Dissertation, University of Connecticut, 1962.

HOLLAND, H. C. The spiral after effect. London: Pergamon Press, 1965.

HOLSEY. B. A. Human physiology'. New York: YcGraw-Hill. 1955.

JEEVES, M. A. Psychological studies of three cases of congenital agenesis of the corpus callosum in man. In CIBA Foundation Study Group No. 20, Functions of the corpus callosum. London: Churchill, 1965. Pp. 73-94.

JEEVES, M. A. A comparison of interhemispheric transmission times in acallosals and normals. Psychonomic Science, $1969,16,245-246$.

MOUNTCASTLE, V. B. Some functional properties of the somatic afferent system. In W. A. Rosenblith (Ed.), Sensory communication. New York: Wiley, 1961. Pp. 403-436.

MYERS, R. E. Function of corpus callosum in interocular transfer. Brain, 1956, 79, 358-363.

PICKERSGILI, M. J., \& JEEVES, M. A. The origin of the after effect of movement. Quarterly Journal of Experimental Psychology, 1964, 16, 90-103.
RICHARDS, W., \& SMITH, R. A. Midbrain as a site for the motion after effect. Nature, 1969 , $223,533-534$

SCOTT, T. R.. \& WOOD, D. Z. Retinal anoxia and the locus of the after-effect. American Journal of Psychology, 1966, 79, 435-442.

SINGER, G., \& DAY, R. H. Interlimb and interjoint transfer of a kinesthetic spatial after effect. Journal of Experimental Psychology, $1966,71,109-114$.

SPERRY, R. W., STAMM, J. S., \& MILNER, N. Relearning test for interocular transfer following division of optic chiasma and corpus callosum in cats. Journal of Comparative \& Physiological Psychology, 1956, 40, 529-533. TAYLOR, M. M. Tracking the decay of the after-effect of seen rotary movement. Perceptual \& Motor Skills, 1963, 16, 119-129. WALLS, G. L. Interocular transfer of after images. American Joumal of Optometry, $1953,30,57-64$.

WOHLGEMUTH, A. On the after effect of seen movement. British Journal of Psychology, Monograph, 1911, 1, 1-117.

\section{NOTE}

1. For acallosal S 3 , the test field was the now-stationary stimulus field.

2. Dixon, N. F. Simultaneous storage of contrary movement aftereffects. In preparation.

\title{
Aggression as a function of vulnerability to attack
}

\author{
RICHARD MERRICK and STUART P. TAYLOR \\ Kent State University, Kent, Ohio 44240
}

Thirty high-need achievers and thirty low-need achievers competed in a task involving reaction time with opponents who attempted to give them increasing shocks. It was observed that counteraggression varied as a function of the degree to which $S$ was vulnerable to the opponent's attack. All conditions of vulnerability evidenced an increase in counteraggression. However, as predicted, the equal-vulnerability condition evidenced the greatest increase in aggression. Achievement motivation had little effect on aggression.

Epstein \& Taylor (1967) recently reported results that suggest that the intensity of counteraggression is a multiplicative function of the victim's vulnerability to attack and the intensity of attack. In this experiment, Ss were told they were competing with an "opponent" on a task involving reaction time and that the $\mathrm{S}$ with the slower reaction time on a trial was to receive a shock of an intensity set by his opponent before the trial. The authors allowed Ss to encounter two types of opponents: those who set the lowest shock settings and those who set the highest shock settings. The Ss were divided equally among three conditions: (1) high vulnerability to the potential attack because of relatively "inferior" performance on the task, (2) low vulnerability because of relatively "superior" performance, and (3) equal vulnerability because of performance equal to the opponent's.

According to the results of this experiment, Ss behaved in a nonaggressive manner toward nonaggressive opponents under all conditions of vulnerability. Given the traditional assumption that the inhibition of aggression is a function of anticipation of punishment, it was predicted that the most intense expression of aggression would have occurred in the low-vulnerability condition. Although Ss were moderatley aggressive toward all aggressive opponents, surprisingly, they expressed the most intense aggressiveness toward the aggressive opponent whose vulnerability was equal to that of their own.

The primary purpose of this experiment was to determine the reliability of the above results and to gather further information concerning the effects of attack and vulnerability on physical aggression. Ss were placed in the three conditions of vulnerability employed by Epstein and Taylor, but rather than competing with either aggressive or nonaggressive opponents, these' Ss encountered opponents who became increasingly aggressive. In view of the results obtained by Epstein and Taylor, the following hypotheses were made: (1) differences in aggressiveness among conditions of vulnerability would increase as a function of attack, and (2) the equal-vulnerability condition would evidence the greatest increase in aggression as a function of attack.

The secondary purpose of this experiment was to determine the relationship between achievement motivation and aggressive behavior. While the possibility of a relationship between these variables has never been empirically explored, it has been suggested by much of the work done in this area (Murray, 1938 ; McClelland, 1961; Reisman, Glazer, \& Denny, 1950; Rotter, 1954).

\section{SUBJECTS}

Ss were male undergraduates enrolled in an introductory psychology course at Kent State University. The extreme groups of Ss were selected from a total of 400 males given the EPPS (Edwards, 1959). The final selection of Ss consisted of $30 \mathrm{Ss}$ with the highest score on the achievement scale and $30 \mathrm{Ss}$ with the lowest score on the achievement scale. The mean achievement scores for the high-and low-achievement groups were 20.29 and 9.51 . respectively. 